\title{
Patterns of peritoneal dissemination and response to systemic chemotherapy in common and rare peritoneal tumors treated by cytoreductive surgery: Study protocol of a prospective, multi-center, observational study
}

\author{
(PRECINCT- Patterns of peritoneal dissemination and REsponse to Chemotherapy IN \\ patients undergoing CyToreductive surgery)
}

Aditi Bhatt MS, MCh. ${ }^{1}$, Pascal Rousset MD, $\mathrm{PhD}^{2}$, Dario Baratti MD, $\mathrm{PhD}^{3}$, Daniele Biacchi MD, $\mathrm{PhD}^{4}, \mathrm{Nazim}$ Benzerdjeb $\mathrm{MD}^{5}, \mathrm{PhD}^{3}$, Ignace de Hingh $\mathrm{MD}, \mathrm{PhD}^{6}$, Marcello Deraco $\mathrm{MD}^{3}$, Vadim Gushcin $\mathrm{MD}^{7}$, Praveen Kammar MS, MCh. ${ }^{8}$, Daniel Labow MD ${ }^{9}$, Edward Levine $\mathrm{MD}^{10}$, Brendan Moran $\mathrm{MD}^{11}$, Faheez Mohamed MD, FRCS $^{11}$, David Morris MD PhD ${ }^{12}$, Sanket Mehta DNB ${ }^{8}$, Aviram Nissan MD ${ }^{13}$, Mohammad Alyami MD ${ }^{14}$, Mohammad Adileh $\mathrm{MD}^{13}$, Shoma Barat $\mathrm{MD}^{12}$, Almog Ben Yacov MD ${ }^{13}$, Kurtis Campbell MD ${ }^{7}$, Kathleen Cummins-Perry $\mathrm{MS}^{10}$, Delia Cortes-Guiral MD, $\mathrm{PhD}^{14}$, Noah Cohen MD ${ }^{9}$, Loma Parikh MD ${ }^{15}$, Samer Alammari $\mathrm{MD}^{14}$, Galal Bashanfer MD ${ }^{16}$, Anwar Alshukami MD ${ }^{17}$, Kaushal Kundalia MD ${ }^{11}$, Gaurav Goswami $\mathrm{DNB}^{18}$,Vincent Van de Vlasakker $\mathrm{MD}^{6}$, Michelle Sittig RN ${ }^{7}$, Paolo Sammartino MD, $\mathrm{PhD}^{4}$, Armando Sardi $\mathrm{MD}^{7}$, Laurent Villeneuve MBE, $\mathrm{PhD}^{19}$, Kiran Turaga MD, $\mathrm{MPH}^{20}$, Yutaka Yonemura MD, $\mathrm{PhD}^{21}$, Olivier Glehen MD, PhD. ${ }^{22}$

\footnotetext{
${ }^{1}$ Dept. of Surgical Oncology, Zydus Hospital, Ahmedabad, India

${ }^{2}$ Dept. of Radiology, Centre Hospitalier Lyon-sud, Lyon, France

${ }^{3}$ Dept. of Surgical Oncology, Fondazione IRCCS Istituto Nazionale dei Tumori, Milan, Italy

${ }^{4}$ Dept. of Surgical Oncology, Sapienza University of Rome, Rome, Italy

${ }^{5}$ Dept. of Pathology, Centre Hospitalier Lyon-sud, Lyon, France

${ }^{6}$ Dept. of Surgical Oncology, Catharina Hospital, Eidhoven, Netherlands

${ }^{7}$ Dept. of Surgical Oncology, Mercy Medical Centre, Baltimore, USA

${ }^{8}$ Dept. of Surgical Oncology, Saifee Hospital, Mumbai, India

${ }^{9}$ Dept. of Surgical Oncology, Mount Sinai Hospital, New York, USA

${ }^{10}$ Dept. of Surgical Oncology, Wake Forest School of Medicine, Winston-Salem, USA

${ }^{11}$ Dept. of Surgical Oncology, Peritoneal Malignancy Institute, Basingstoke, UK

${ }^{12}$ Dept. of Surgical Oncology, St. George Hospital, Sydney, Australia

${ }^{13}$ Dept. of Surgical Oncology, Sheba Medical Centre, Telshomer, Israel

${ }^{14}$ Dept. of Surgical Oncology, King Khaled Hospital, Najran, Saudi Arabia

${ }^{15}$ Dept. of Pathology, Zydus Hospital, Ahmedabad, India

${ }^{16}$ Dept. of Pathology, King Khaled Hospital, Najran, Saudi Arabia

${ }^{17}$ Dept. of Radiology, King Khaled Hospital, Najran, Saudi Arabia

${ }^{18}$ Dept. of Radiology, Zydus Hospital, Ahmedabad, India

${ }^{19}$ Dept. of Clinical Research, Centre-hospitalier Lyon-sud, Lyon, France

${ }^{20}$ Dept. of Surgical Oncology, University of Chicago Medical Centre, Chicago, USA

${ }^{21}$ Dept. of Surgical Oncology, Kishiwada Tokashukai Hospital, Osaka, Japan

${ }^{22}$ Dept. of Surgical Oncology, Centre Hospitalier Lyon-sud, Lyon, France
}

NO殸: This preprint reports new research that has not been certified by peer review and should not be used to guide clinical practice. 
45 Corresponding author Dr. Aditi Bhatt MS, MCh.,

46 Department of Surgical oncology, Zydus hospital,

47 Thaltej, Ahmedabad-380054

48 India. Phone- 917966210200

49 E-mail- aditimodi31@gmail.com

50

51

53 Words- 4000

54 Figures-2

55 Tables -5

56 References-36

57

58

59

60

61

62

63

64

65

66

67

68

69

70

71

72

73

74

75

76

77

78

79

80

81

82

83

84

85

86

87

88 


\section{Abstract}

90

91

\section{Introduction}

92 Despite optimal patient selection and surgical effort, recurrence is seen in over $70 \%$ of

93 patients undergoing cytoreductive surgery(CRS) for peritoneal metastases (PM). Apart from

94 the peritoneal cancer index(PCI), completeness of cytoreduction and tumor grade, there are

95 other factors like disease distribution in the peritoneal cavity, pathological response to

96 systemic chemotherapy(SC), lymph node metastases and morphology of PM which may have

97 prognostic value. One reason for the underutilization of these factors is that they are known

98 only after surgery. Identifying clinical predictors, specifically radiological predictors, could

99 lead to better utilization of these factors in clinical decision making and the extent of

100 peritoneal resection performed for different tumors. This study aims to study these factors,

101 their impact on survival and identify clinical and radiological predictors.

\section{Methods and analysis}

103 There is no therapeutic intervention in the study. All patients with biopsy proven PM from

104 colorectal, appendiceal, gastric and ovarian cancer and peritoneal mesothelioma undergoing

105 CRS will be included. The demographic, clinical, radiological, surgical and pathological

106 details will be collected according to a pre-specified format that includes details regarding

107 distribution of disease, morphology of PM, regional node involvement and pathological

108 response to SC. In addition to the absolute value of PCI, the structures bearing the largest

109 tumor nodules and a description of the morphology in each region will be recorded. A

110 correlation between the surgical, radiological and pathological findings will be performed

111 and the impact of these potential prognostic factors on progression-free and overall survival

112 determined. The practices pertaining to radiological and pathological reporting at different

113 centers will be studied. 


\section{Ethics and dissemination}

116 The study protocol has been approved by the Zydus Hospital ethics committee $\left(27^{\text {th }}\right.$ July,

117 2020) and Lyon-sud ethics committee (A15-128). It is registered with the clinical trials

118 registry of India (CTRI/2020/09/027709).

119 The results will be published in peer-reviewed scientific journals.

120 Strength and limitations

121 - A prospective correlation between the radiological, surgical and pathological findings

122 in patients undergoing CRS will be performed which has not been done before.

123 - Being prospective in nature it will also enable us to evaluate the impact of the current

124 treatment practices on the clinical end-points

- There is fixed protocol for radiological and pathological evaluation for which there

$126 \quad$ are no specific guidelines

127 - The data collection format will capture all the relevant data but this may affect

$128 \quad$ compliance.

129 - Despite the large sample size planned for each primary site, the heterogeneity of

130 treatment protocols may be a limiting factor while evaluating the impact on survival.

131

132

133 
medRxiv preprint doi: https://doi.org/10.1101/2021.04.01.21254760; this version posted April 7, 2021. The copyright holder for this preprint (which was not certified by peer review) is the author/funder, who has granted medRxiv a license to display the preprint in perpetuity.

It is made available under a CC-BY-NC-ND 4.0 International license .

\section{$139 \underline{1.0}$ Introduction}

140 A wide variety of primary tumors give rise to peritoneal metastases (PM). Over the last

141 couple of decades, the management of PM has undergone a radical change. Cytoreductive

142 surgery (CRS) with, or without, some form of intraperitoneal chemotherapy has led to a

143 major increase in survival, and cure in some patients. [1] Recurrence after CRS, however, is

144 common and occurs in around $70 \%$ of the patients irrespective of the primary tumor site. [2,

$1453,4]$ For all types of peritoneal malignancies the peritoneal cancer index (PCI) and the

146 completeness of cytoreduction (CC-score) have emerged as the most important prognostic

147 factors and are used for selecting patients for surgery. [5] The third major factor is disease

148 biology, previously determined mainly by the histological subtype and/or grade and in more

149 recent times using one or more molecular markers (for e.g. KRAS, BRAF and MSI for

150 colorectal PM, BRCA mutations for ovarian cancer). [6] The main role of molecular markers,

151 however, is in selecting patients for systemic therapies. In colorectal PM this is largely

152 because there is limited evidence regarding the benefit of surgery in patients with tumors

153 expressing poor prognostic markers. Apart from the grade of the tumor, pathological factors

154 have been underutilized in selecting patients for surgery. The prognostic impact of the

155 pathological response to systemic chemotherapy (SC) has been demonstrated for both

156 colorectal PM and ovarian cancer. [7, 8] This, however, has not been utilized in clinical

157 decision making. One reason could be that such factors are known only after the surgery has

158 been completed. There are gaps in our knowledge of patterns of disease distribution and

159 morphology of PM and results of experimental studies have not been evaluated in the clinical

160 setting. $[9,10]$ In our preliminary study, we found a high incidence of regional lymph node

161 involvement related to both the primary tumor and peritoneal disease. [11] All these factors,

162 determined on pathological evaluation, could have a prognostic impact and could influence

163 both patient selection and the extent of surgery performed. 
medRxiv preprint doi: https://doi.org/10.1101/2021.04.01.21254760; this version posted April 7, 2021. The copyright holder for this preprint (which was not certified by peer review) is the author/funder, who has granted medRxiv a license to display the preprint in perpetuity.

It is made available under a CC-BY-NC-ND 4.0 International license .

164 Similarly, imaging has been used for determining the disease extent pre-operatively. As

165 expected there is under-prediction of the PCI due to limitations of modern imaging modalities

166 like MRI in detecting tiny peritoneal nodules $(<5 \mathrm{~mm})$. The other information that can be

167 derived from imaging, such as morphology of PM and disease distribution in the peritoneal

168 cavity, has not been adequately explored for its potential clinical implications. Surgical

169 decision making regarding the extent of resection is made on intra-operative visualization of

170 peritoneal disease which has been reported to be inaccurate in a large proportion of the

171 patients. $[12,13]$ There is no consensus on the extent of peritoneal resection that should be

172 performed for each primary tumor. [14] And early recurrence could be due to the failure to

173 address all the occult disease effectively with surgery. A better understanding of the disease

174 distribution and mechanisms of peritoneal dissemination may help in standardizing the extent

175 of resection for different primaries.

176 Correlation of the clinical radiological, surgical and pathological findings could provide new

177 insights about peritoneal disease distribution, mechanisms of spread and potential impact of

178 these prognostic factors on the treatment of patients with PM.

179 Hence, this study has been conceived and is being conducted with the following goals

180 - To study patterns of peritoneal disease distribution, lymph node metastases,

181 morphology of PM and pathological response to SC in patients undergoing

$182 \quad$ CRS.

183 - To study the impact of these factors on survival.

184 - To identify clinical and radiological predictors of these factors by performing

185 a correlation between the radiological, surgical and pathological findings.

186 - To study the existing practices related to evaluation of disease extent on

187

188 imaging, intra-operatively and on pathology and the extent of peritoneal resection performed for each tumor. 
medRxiv preprint doi: https://doi.org/10.1101/2021.04.01.21254760; this version posted April 7, 2021. The copyright holder for this preprint (which was not certified by peer review) is the author/funder, who has granted medRxiv a license to display the preprint in perpetuity.

It is made available under a CC-BY-NC-ND 4.0 International license .

- To study the practices related to pathological evaluation of CRS specimens.

\section{$191 \quad$ 2.0 Methods}

192 This is a prospective, multi-centre observational study. There is no therapeutic intervention.

193 All the patients with biopsy proven PM from colorectal, appendiceal, gastric and ovarian

194 cancer or with peritoneal mesothelioma undergoing CRS with, or without, intraperitoneal

195 chemotherapy will be included. Informed consent will be taken from all patients. The

196 demographic, clinical, radiological, surgical and pathological details will be collected

197 according to a pre-specified format that includes details regarding the distribution of disease,

198 morphology of PM, regional node involvement and pathological response to SC.

199 There are currently no reporting guidelines for both imaging and pathological evaluation of

200 CRS specimens. The information captured can vary from center to center though the

201 parameters analyzed are the same. The reporting format in this study (supplement 1)

202 includes calculation of the radiological PCI and other details like the sites and structures

203 bearing the largest tumor nodules and a description of the morphology in each region.

204 Similarly, the surgical findings will be documented in a systematic pre-specified manner. To

205 ensure uniformity in the morphological description, a list of morphological features has been

206 made for each for the radiological, surgical and pathological evaluations. This description

207 has to be provided with the lesion score for each region of the PCI. The first 6 months of the

208 study comprise a test phase in which teams will see the feasibility and compliance of this

209 form of data capturing. Based on the inputs from the participating centers, if required, some

210 modifications will be made in the format of data collection. During the second phase, there

211 will be an addition to the protocol for pathological evaluation in which pathologists will be

212 required to take additional sections from the 'normal appearing' peritoneum adjacent to 
medRxiv preprint doi: https://doi.org/10.1101/2021.04.01.21254760; this version posted April 7, 2021. The copyright holder for this preprint (which was not certified by peer review) is the author/funder, who has granted medRxiv a license to display the preprint in perpetuity.

It is made available under a CC-BY-NC-ND 4.0 International license .

213 tumor nodules. Centers in which it is not possible to follow this protocol will continue to

214 follow the protocol of the first phase. The study flow-chart is in figure $\mathbf{1}$.

$215 \quad 2.1$ Inclusion and exclusion criteria

- Patient undergoing debulking procedures will be included

- Patients undergoing palliative procedures that do not involve tumor debulking will be excluded unless the goal of surgery was to obtain a complete cytoreduction i.e. procedures performed with the intention of palliation alone like a diverting stoma will be excluded.

- For ovarian cancer, only patients with FIGO stage III-C or IV-A will be included. Patients undergoing surgery at first diagnosis, after neoadjuvant chemotherapy (NACT) and those undergoing surgery for recurrent disease will be included. Patients

\subsection{End points}

233 Primary end points: The primary end point is disease distribution in the peritoneal cavity.

234 Disease distribution in the peritoneal cavity will be captured in detail on imaging, during

235 surgery and on pathology. The confirmation of disease on pathology will be considered as

236 confirmatory for presence of disease in each region. If only debulking is performed, for

237 regions which are not addressed during surgery, the surgical evaluation will be considered. 
238 The abdominal cavity is divided into 13 regions according to Sugarbaker's PCI and the

239 structures in each region are defined using the PROMISE internet application to ensure

240 uniformity in reporting. [15, 16] Apart from the main data collection spreadsheet, separate

241 forms have been created for the radiological, surgical and pathological evaluation to

242 facilitation capturing of the disease distribution (supplements 2-4).

243 Secondary end points: The secondary end-point are

244 1. Pathological response to systemic chemotherapy: This will be evaluated for all patients

245 receiving NACT for PM. Different scores will be used for different primary tumors as

246 described in the section on pathological evaluation.

247 2. Regional lymph node involvement: Both regional nodes in relation to the primary and

248 those in relation to the PM are considered as regional nodes (Supplement 1). [11]

249 3. Morphology of peritoneal metastases: The morphological description for each region on

250 imaging, during surgery and pathology will be documented (Table 1). In phase two, presence

251 of disease in adjacent normal peritoneum will be considered an additional morphological

252 feature.

253 4. Overall survival: overall survival (OS) will be calculated from the date of surgery

254 5. Progression-free survival- progression-free survival (PFS) will be calculated from the

255 date of surgery

$256 \quad 2.3$ Recruitment period

257 - $1^{\text {st }}$ Phase: $15^{\text {th }}$ Sept $2020-14$ th $^{\text {st }}$ March 2021

$258 \quad-2^{\text {nd }}$ Phase: $15^{\text {tt }}$ March 2021- 14 th $^{\text {th }}$ Sept 2022

2592.4 Study duration- The total duration of the study is 7 years; the first two years for

260 recruitment and another 5 years for follow-up.

2612.5 Surgical procedures 
262 All surgical procedures will be performed with the goal of complete cytoreduction. [17]

263 Patients undergoing planned debulking procedures will also be included. According to

264 current surgical standards, only involved regions of the peritoneum or those bearing visible

265 disease will be resected. Some regions like the falciform ligament, umbilical round ligament,

266 lesser and greater omenta may be resected in the absence of visible disease as these structures

267 have a high probability of harboring occult disease. These regions will be considered "normal

268 appearing' regions during surgical and pathological evaluation. At some centers, based on

269 institutional policies and/or as part of an ongoing study, removal of the entire parietal

270 peritoneum is performed for primary tumors such as mesothelioma, appendiceal and ovarian

271 cancer to address occult disease. $[18,19]$ The peritoneal regions resected thus will be marked

272 as 'normal appearing' regions.

273 The peritoneal lesions will be classified as nodules, plaques, confluent deposits, thickening,

274 adhesions or scarring by the surgeon and given a lesion score accordingly (Table 1). The

275 largest deposit in each region of the PCI will have to be categorized thus, and the lesion score

276 mentioned. The details of the peritonectomy procedures and visceral resections performed

277 will be recorded.

\section{$278 \quad 2.6$ Imaging protocol}

279 CT scan with or without oral and iv contrast, FDG-PET CT scan (with IV contrast) and

280 peritoneal MRI are all acceptable imaging modalities. A combination of the above may be

281 performed. Where the facilities and expertise are available, peritoneal MRI is the preferred

282 modality for evaluating the peritoneal disease. [20] Both T1 and T2, gadolinium enhanced

283 and diffusion weighted images will be used to map the peritoneal disease. The protocol and

284 sequences have been described in detail elsewhere and can be referred to. [20] When used in

285 combination with MRI, oral contrast may be omitted while performing a CT scan. A slice

286 thickness of $0.6-5 \mathrm{~mm}$ is acceptable. If the whole thorax is not included, at least the lower 
medRxiv preprint doi: https://doi.org/10.1101/2021.04.01.21254760; this version posted April 7, 2021. The copyright holder for this preprint (which was not certified by peer review) is the author/funder, who has granted medRxiv a license to display the preprint in perpetuity.

It is made available under a CC-BY-NC-ND 4.0 International license .

thorax will be included.

288 Pre-operative imaging will be preferably performed within two to four weeks of the planning surgical procedures. All scans performed will be considered while evaluating both the presence or absence and extent of disease.

Imaging features suggestive of peritoneal metastases include peritoneal nodules, thickening, or fat stranding. The morphological classification is listed in Table 1.

293 There are two areas that are elaborated on here.

294 The first is disease related peritoneal thickening. Normal peritoneal tissues are relatively

295 thin measuring $<3 \mathrm{~mm}$ in thickness and typically show only no, or mild, enhancement that is

296 less than or equal to that of the liver parenchyma. Obvious thickening, all the more if

297 irregular or nodular, as well as marked peritoneal enhancement will be considered as

298 peritoneal metastases (in proven cases of peritoneal metastases). Confluent nodules will be

299 given a lesion score of 3 (Supplement 2).

300 Infiltration of the adipose tissue (whatever the structure involved-- mesentery -omentum -

301 ligaments -mesocolon) will be be reported as "suggestive of peritoneal metastases" if at least

302 confluent or pseudo-nodular in some areas, or nodular or mass-like. In the absence of diffuse

303 mass-like disease scored 3 (e.g. omental cake), the lesion will be scored considering it as

304 focal in the absence of measurable lesions. It will be scored 2 even if $>5 \mathrm{~cm}$ to avoid

305 overestimation due to a misleading effect of resorption. If the maximum length of soft tissue

306 is considered, it will be scored 2 if less than $5 \mathrm{~cm}$ and 3 if more than $5 \mathrm{~cm}$.

\section{$307 \quad 2.7$ Pathological evaluation}

308 There are no guidelines or recommendations for evaluation of CRS specimens and each 309 center will follow their existing protocols. [21] The evaluation should involve analysis of 
medRxiv preprint doi: https://doi.org/10.1101/2021.04.01.21254760; this version posted April 7, 2021. The copyright holder for this preprint (which was not certified by peer review) is the author/funder, who has granted medRxiv a license to display the preprint in perpetuity.

It is made available under a CC-BY-NC-ND 4.0 International license .

310 each peritoneal region submitted for evaluation separately. Similarly, all viscera should be

311 evaluated individually. Centers where such an evaluation is not performed, or that cannot

312 evaluate the specimens in this manner, were excluded from the study. One important aspect is

313 calculation of the pathological PCI. [22] For the pathological PCI, the pathologist has to

314 specify the size of the largest tumor deposit in the region in millimeters. The presence of

315 disease in confirmed on microscopy. If there is no disease on microscopic examination, the

316 lesion score is zero. The pathological response grade is mentioned for each of the thirteen

317 regions. The method of calculating the pathological PCI is described in Figure 2.

318 In the second phase, there will be an intervention in the pathological evaluation. For every

319 region that is submitted to the pathologist, additional sections will be taken from the normal

320 peritoneum at a distance of at least $5 \mathrm{~mm}$ and preferably $10 \mathrm{~mm}$ from the tumor nodule. This

321 evaluation is termed as evaluation of 'normal peritoneum around tumor nodules'. This part of

322 the study is not mandatory as institutional policies, time constraints and the cost involved

323 may prevent centers performing this part of the study.

324 The following scores for evaluation for pathological response to SC will be used

325 For ovarian cancer, the chemotherapy response score by Bohm et al has been validated in

326 multiple studies and is the preferred score. It is described in Table 2. [23]

327 The peritoneal regression grading score by Solass et al was developed for patients undergoing

328 PIPAC and has been externally validated (Table 3). [24, 25] It can be used for any of the

329 primary tumors.

330 For colorectal PM, the score developed at Lyon-sud is an alternative as it is specific for

331 colorectal PM but has not been externally validated (Table 4). [26] The mean of scores in

332 each region is computed and is the final score. In addition, the type of response is classified

333 as fibrosis, infarct like necrosis or a colloid response. A combination of the three types of

334 response can be present in a given region. 
medRxiv preprint doi: https://doi.org/10.1101/2021.04.01.21254760; this version posted April 7, 2021. The copyright holder for this preprint (which was not certified by peer review) is the author/funder, who has granted medRxiv a license to display the preprint in perpetuity.

It is made available under a CC-BY-NC-ND 4.0 International license .

335 Use of scores apart from the above is permitted and the details of the same have to be

336 provided. It would be ideal to have the same score for each primary at all centers but that

337 again may not be possible. Secondly, the main focus will be a pathological complete response

338 which does not have different criteria across the scores. Regional and peritoneal nodes will be

339 evaluated as previously described.[11]

341 The reporting of other pathological findings like evaluation of the primary tumor, if present,

342 grade or pathological classification will be according to the existing protocols at each center

343 and will be captured in the data form. Similarly, the molecular markers that have been tested

344 will be recorded with the test results. Performing specific molecular tests is not binding.

\section{$345 \quad 2.8$ Follow up}

346 The follow-up of patients will be performed according to the existing protocols at each

347 centers. Centers will be asked to provide a follow-up of their patients at 1,3 and 5 years after

348 completion of the recruitment. The information will include the disease status, date of

349 detection and site of recurrent disease, subsequent therapies administered, date and cause of

350 death.

\section{$351 \quad 3.0$ Sample size}

352 The number of patients required was determined based on our preliminary study looking at

353 the disease distribution in relation to the disease extent. We considered involvement of

354 different regions in relation to the surgical PCI as well as different structures in relation to the

355 surgical PCI for each primary tumor. In addition, consideration was given to another end-

356 point, that is pathological response to SC. This was relevant only for colorectal cancer and

357 ovarian cancer. For colorectal cancer, upper regions (1-3 of Sugarbaker's PCI) were involved

358 in 20\%. [27] All patients with involvement of these regions had a surgical PCI of more than

359 10. [27] Thus, to confirm this finding in a larger series with $80 \%$ predictive power and alpha 
medRxiv preprint doi: https://doi.org/10.1101/2021.04.01.21254760; this version posted April 7, 2021. The copyright holder for this preprint (which was not certified by peer review) is the author/funder, who has granted medRxiv a license to display the preprint in perpetuity.

It is made available under a CC-BY-NC-ND 4.0 International license .

360 error of 0.05 , we would require 35 patients with a PCI $<10$ and 35 with a PCI $>10$.

361 Considering that $70 \%$ of the patients have a PCI $<10$ in those undergoing CRS, we would

362 have to recruit over 100 patients. The incidence of involvement of the umbilical round

363 ligament similarly, was $2 \%$ and we would have to recruit around 340 patients to confirm this.

364 [27] For colorectal PM, few studies have evaluated the role of the pathological response to

365 SC. The reported incidence of a pathological complete response (pCR) ranges from 10-15\%.

366 [26] In our recent analysis (unpublished data) it was 25\%. In the same study, we could not

367 find any factors that had a significant impact on the incidence of pCR except the type of

368 chemotherapy used. To study the impact of 5-7 relevant factors we would need about 70

369 patients with a pCR. If we consider the incidence to be between 15 and 25, around 350

370 patients with colorectal PM receiving NACT will be required. Thus, the number of colorectal

371 cancer patients we need to recruit in the study was set at 500 considering that around $70-80 \%$

372 will receive NACT.

373 For ovarian cancer, the incidence of a near complete/complete response or a Bohm score of 3

374 is around $15 \%$ in various published reports. [23] Many studies have explored predictors of a

375 complete response and to date no factor has been found to have a significant impact. To

376 determine the impact of 5 factors, 350 patients undergoing interval CRS alone would be

377 needed. Considering the disease distribution, 120 patients undergoing primary CRS and CRS

378 for recurrence each are required to be recruited. Thus 600 patients with ovarian cancer will be

379 recruited. For peritoneal mesothelioma, 100 patients are required with numbers for gastric

380 cancer being 100 patients and for appendiceal mucinous tumors/pseudomyxoma peritonei

381 (PMP), 300 patients (Table 5). These numbers also account for the variable histology,

382 incidence of disease in different structures and regions that are crucial to studying the

383 patterns of peritoneal dissemination. 
medRxiv preprint doi: https://doi.org/10.1101/2021.04.01.21254760; this version posted April 7, 2021. The copyright holder for this preprint (which was not certified by peer review) is the author/funder, who has granted medRxiv a license to display the preprint in perpetuity.

It is made available under a CC-BY-NC-ND 4.0 International license .

384 The study will continue for the stipulated time period even if the target numbers are recruited

385 in a shorter period.

\section{4.0 Statistical methods}

387 Categorical data will be described as number (\%). Non-normally distributed continuous data

388 will be expressed as the median and range. Categorical data will be compared with the $\mathrm{x}^{2}$

389 test. For comparison of parametric data, the student $\mathrm{t}$ test and for non-parametric data, the

390 Mann Whitney U test will be used. The impact of various prognostic variables like age, sex,

391 primary tumour site, grade, primary tumour stage, PCI, timing of PM and NACT on the

392 primary and secondary clinical end-points, namely disease distribution, pathological response

393 to SC, morphology of PM and regional lymph node involvement will be studied. Multivariate

394 logistic regression analysis will be performed to test the impact of multiple factors on these

395 end-points. For studying the disease distribution, the peritoneal regions will be divided into

396 four groups- upper regions comprising of regions 1,2,3, middle regions comprising of regions

3970,4 and 8 , lower regions comprising of regions 5, 6, 7 and small bowel regions comprising of

398 regions 9-12 of Sugarbaker's PCI. [16]

399 Previous studies have shown the negative prognostic impact of involvement of some regions

400 like the upper regions and small bowel regions on survival.[28,29] The impact of

401 involvement of these regions on survival will be evaluated as well. In addition, the

402 involvement of some specific structures and regions like the omentum, right upper quadrant

403 or region 1 will be considered separately.

404 Cox proportional hazard regression will be used to describe the association between

405 individual risk factors, including the 4 pathological prognostic variables, on PFS and OS

406 both, in terms of hazard ratio and its $95 \%$ confidence interval (CI). Multivariate Cox

407 regression will be used to assess the impact of risk factors on survival. A p-value of $<0.05$ 
medRxiv preprint doi: https://doi.org/10.1101/2021.04.01.21254760; this version posted April 7, 2021. The copyright holder for this preprint

(which was not certified by peer review) is the author/funder, who has granted medRxiv a license to display the preprint in perpetuity.

It is made available under a CC-BY-NC-ND 4.0 International license .

408 will be considered statistically significant. PFS and OS will be calculated from the date of

409 surgery.

410 For identifying clinical predictors of these pathological prognostic factors, clinical and

411 radiological variables will be considered. One of the important variables is the PCI

412 (radiological and surgical). To test the performance of the radiological and surgical PCI, a

413 comparison will be made with the pathological PCI for each of the two and also between the

414 surgical and radiological PCI. A difference of 0-3 points will be considered as concordance.

415 The comparison will be made between the total value and score in each region. The

416 performance will be expressed in terms of false positives and negatives, true positives and

417 negatives, sensitivity and specificity. Receiver operating characteristic (ROC) curves will be

418 used to determine cut-off values of PCI to predict end-points like a pathological complete

419 response.

420 PCI will also be evaluated as a categorical variable.

\section{$421 \quad 5.0$ Ethics and dissemination}

422 This study was approved by the Zydus hospital (institution of the first author) ethics

423 committee on the $27^{\text {th }}$ July 2020 . At Lyon-sud hospital, this study is being carried out within

424 the framework of the RENAPE observational registry (CNIL-no. DR-2010-297) and the

425 BIG- RENAPE registry (NCT NCT02823860), IRB number A15-128. [30] Subsequently,

426 approval was obtained at other centres according to the existing institutional policies.

427 The proposed analyses will be carried out during the course and after completion of the study

428 and the results published in peer-reviewed scientific journals. 
medRxiv preprint doi: https://doi.org/10.1101/2021.04.01.21254760; this version posted April 7, 2021. The copyright holder for this preprint (which was not certified by peer review) is the author/funder, who has granted medRxiv a license to display the preprint in perpetuity.

It is made available under a CC-BY-NC-ND 4.0 International license .

\section{$430 \quad 6.0$ Patient and public involvement}

431 No patient involved

\section{$432 \quad 7.0$ Registration}

433 The study is registered with the clinical trials registry of India (CTRI/2020/09/027709).

\section{$434 \quad$ 8.0 Discussion}

435 This study includes a prospective correlation between the radiological, surgical and

436 pathological findings in patients undergoing CRS. The main goal is to determine prognostic

437 impact of factors like disease distribution in the peritoneal cavity, pathological response to

438 SC, lymph node metastases and morphology of PM. Correlation with clinical and

439 radiological evaluation will be performed to identify predictors. The results could have a

440 bearing, not just on the patient selection for surgery, but also the extent of peritoneal

441 resection performed. Currently, the same surgical principles are applied to PM arising from

442 different primary tumors, largely based on the surgical principles that were initially

443 developed for pseudomyxoma peritonei (PMP) for which these procedures were first

444 performed [31] It has been proposed that the surgical strategy should differ according to the

445 primary tumor site. [32] The prognostic impact of pathological response to SC, involvement

446 of specific regions of the peritoneal cavity and regional node involvement has been

447 demonstrated previously for some primaries. [23, 33, 34] This study will look at these factors

448 prospectively for all primary sites. This will be the first study to correlate the morphology on

449 imaging and visual inspection with presence, or absence, of disease on pathology. For

450 example, previous studies have looked at the false negative and false positives comparing the

451 surgical lesion score and pathological finding. [35, 36] However, different surgeons will

452 score different morphological appearances differently; some may give a lesion score of 0 to 
medRxiv preprint doi: https://doi.org/10.1101/2021.04.01.21254760; this version posted April 7, 2021. The copyright holder for this preprint (which was not certified by peer review) is the author/funder, who has granted medRxiv a license to display the preprint in perpetuity.

It is made available under a CC-BY-NC-ND 4.0 International license .

453 scarring, others may score it 1 . The pathological PCI is a potential prognostic marker and is

454 not calculated by many centers. If its prognostic value is demonstrated in this study, a

455 simplified format of calculating it will be needed for other centers to be able to compute it.

456 The results will provide information currently missing in the scientific literature regarding

457 disease distribution in the peritoneal cavity in different primary tumors. It will differ from

458 previous reports as a correlation with the PCI will be performed. Similarly, there is little

459 information available about the regional lymph node involvement in relation to peritoneal

460 disease. Nodal involvement in patients undergoing CRS can be in relation to the primary

461 tumor if the primary is in situ or secondary to peritoneal disease. [11] Pelvic nodes, hepatic

462 hilar nodes, greater and lesser omental nodes are some regional nodes that are involved

463 secondary to peritoneal disease. Whilst regional nodes form part of staging of peritoneal

464 mesothelioma, their involvement has not been studied in other tumors though surgeons often

465 resect these nodes during CRS. Based on the results, the extent of peritoneal resection and

466 regional lymphadenectomy that is performed can be determined for each primary tumor. The

467 participating centers are some of the most experienced centers in treating peritoneal

468 metastases and thus, though different treatment strategies will be employed at each center,

469 their impact can be studied.

470 The format for data collection is exhaustive and designed to capture all relevant information.

471 This may, however, become a limitation of the study as compliance will be a problem. The

472 initial protocol underwent several modifications based on the inputs from each center before

473 being finalized. Another review will be performed during the first phase and alterations made

474 in the format of capturing data if the need arises. Despite the large sample size planned for

475 each primary site, the heterogeneity of treatment protocols may be a limiting factor while

476 evaluating the impact on survival. Nevertheless, the results will provide important insights on

477 disease biology that will in the future influence the way these patients are treated. 
478 Future studies could be performed on more homogeneous cohorts to validate the prognostic

479 factors identified in this study.

480

\section{References}

1. Glehen O, Gilly FN, Boutitie F, Bereder JM, Quenet F, Sideris L, et al. Toward

2. Braam, H.J., van Oudheusden, T.R., de Hingh, I.H., Nienhuijs, S.W., Boerma, D.,

Wiezer, M.J. and van Ramshorst, B. (2014), Patterns of recurrence following complete cytoreductive surgery and hyperthermic intraperitoneal chemotherapy in patients with peritoneal carcinomatosis of colorectal cancer. J. Surg. Oncol., 109: 841-847. doi:10.1002/jso.23597

3. Mercier, F., Dagbert, F., Pocard, M., Goéré, D., Quenet, F., Wernert, R., Dumont, F., 
medRxiv preprint doi: https://doi.org/10.1101/2021.04.01.21254760; this version posted April 7, 2021. The copyright holder for this preprint (which was not certified by peer review) is the author/funder, who has granted medRxiv a license to display the preprint in perpetuity.

It is made available under a CC-BY-NC-ND 4.0 International license .

502 6. Katdare N., Bhatt A., Glehen O. (2020) Biomarkers in the Management of

503 Peritoneal Metastases. In: Glehen O., Bhatt A. (eds) Pathology of Peritoneal

$504 \quad$ Metastases. Springer, Singapore

505 7. Passot G, You B, Boschetti G, Fontaine J, Isaac S, Decullier E, Maurice C, Vaudoyer

506 D, Gilly FN, Cotte E, Glehen O (2014) Pathological response to neoadjuvant

507 chemotherapy: a new prognosis tool for the curative management of peritoneal

$508 \quad$ colorectal carcinomatosis. Ann Surg Oncol 21(8):2608-2614.

509 8. Böhm S, Faruqi A, Said I, Lockley M, Brockbank E, Jeyarajah A et al (2015)

510 Chemotherapy response score: development and validation of a system to quantify

511 histopathologic response to neoadjuvant chemotherapy in tubo-ovarian high-grade

512 serous carcino- ma. J Clin Oncol 33(22):2457-2463.

513 9. Lemoine L, Sugarbaker P, Van der Speeten K. Pathophysiology of colorectal

514 peritoneal carcinomatosis: Role of the peritoneum. World J Gastroenterol.

515 2016;22(34):7692-7707. doi:10.3748/wjg.v22.i34.7692

516 10. Yonemura Y, Kawamura T, Bandou E, Tsukiyama G, Endou Y, Miura M. The natural

517 history of free cancer cells in the peritoneal cavity. In: Gonzalez-Moreno S, editor.

518 Advances in Peritoneal Surface Oncology. Berlin, Germany: Springer- Verlag Berlin

$519 \quad$ Heidelberg, 2007: 11-23

520 11. Bhatt A, Yonemura Y, Benzerdjeb N, Mehta S, Mishra S, Parikh L, Kammar P, et al.

521 Pathological assessment of cytoreductive surgery specimens and its unexplored

522 prognostic potential- a prospective multi-centric study. Eur J Surg Oncol. 2019 July

523 (in press) DOI: https://doi.org/10.1016/j.ejso.2019.07.019

524 12. Bhatt, A., Kammar, P., Sinukumar, S. et al. Total Parietal Peritonectomy Can Be

525 Performed with Acceptable Morbidity for Patients with Advanced Ovarian Cancer 
medRxiv preprint doi: https://doi.org/10.1101/2021.04.01.21254760; this version posted April 7, 2021. The copyright holder for this preprint (which was not certified by peer review) is the author/funder, who has granted medRxiv a license to display the preprint in perpetuity.

It is made available under a CC-BY-NC-ND 4.0 International license .

526 After Neoadjuvant Chemotherapy: Results From a Prospective Multi-centric

527

Study. Ann Surg Oncol (2020). https://doi.org/10.1245/s10434-020-08918-4

528

13. Bhatt, A., Rousset, P., Benzerdjeb, N., Kammar, P., Mehta, S., Parikh, L., Goswami,

G., Shaikh, S., Kepenekian, V., Passot, G. and Glehen, O. (2020), Prospective

530

correlation of the radiological, surgical and pathological findings in patients

531

undergoing cytoreductive surgery for colorectal peritoneal metastases: implications

532

for the preoperative estimation of the peritoneal cancer index. Colorectal Dis..

533

doi: $10.1111 /$ codi.15368

534

535

14. Bhatt, A., Glehen, O. ASO Author Reflections: Tailoring the Extent of Peritoneal

Resection for Peritoneal Metastases According to the Primary Tumor Site. Ann Surg

538

539

15. Jacquet P Sugarbaker PH Current methodologies for clinical assessment of patients

Oncol 27, 1471-1472 (2020). https://doi.org/10.1245/s10434-020-08344-6

16. Villeneuve L, Thivolet A, Bakrin N, Mohamed F, Isaac S, Valette PJ, Glehen with peritoneal carcinomatosis. J Exp Clin Cancer Res. 1996; 15: 49-58

17. Jacquet P, Sugarbaker PH. Clinical research methodologies in diagnosis and staging of patients with peritoneal carcinomatosis. In: Sugarbaker PH, editor. Peritoneal carcinomatosis: principles of management. Boston: Kluwer; 1996. p. 359-74. report peritoneal malignancy extent. PeRitOneal MalIgnancy Stage Evaluation (PROMISE) application. Eur J Surg Oncol. 2016 Jun;42(6):877-82

18. Deraco M, Baratti D, Kusamura S, Laterza B, Balestra MR. Surgical technique of parietal and visceral peritonectomy for peritoneal surface malignancies. J Surg Oncol. 2009;100(4):321-8. 
551 19. Bhatt, A., Kammar, P., Sinukumar, S. et al. Total Parietal Peritonectomy Can Be

552 Performed with Acceptable Morbidity for Patients with Advanced Ovarian Cancer

553 After Neoadjuvant Chemotherapy: Results From a Prospective Multi-centric

554 Study. Ann Surg Oncol (2020). https://doi.org/10.1245/s10434-020-08918-4

555 20. Low RN, Barone RM, Rousset P. Peritoneal MRI in patients undergoing

556 cytoreductive surgery and HIPEC: History, clinical applications, and implementation.

557 Eur J Surg Oncol. 2019 Feb 28. pii: S0748-7983(19)30303-8. doi:

$558 \quad$ 10.1016/j.ejso.2019.02.030.

559 21. Bhatt, A., Mishra, S., Parikh, L. et al. Essentials for Pathological Evaluation of

560 Peritoneal Surface Malignancies and Synoptic Reporting of Cytoreductive Surgery

561 Specimens-A review and evidence-based guide. Indian J Surg Oncol 11, 101-126

562 (2020). https://doi.org/10.1007/s13193-019-00897-7

563 22. Bhatt A, Yonemura Y, Mehta S, et al. The Pathologic Peritoneal Cancer Index (PCI)

564 Strongly Differs From the Surgical PCI in Peritoneal Metastases Arising From

565 Various Primary Tumors. Ann Surg Oncol. 2020;27(8):2985-2996.

566 doi:10.1245/s10434-020-08234-х

568 23. Böhm S, Faruqi A, Said I, Lockley M, Brockbank E, Jeyarajah A et al (2015)

569 Chemotherapy response score: development and validation of a system to quantify

570 histopathologic response to neoad- juvant chemotherapy in tubo-ovarian high-grade

571 serous carcino- ma. J Clin Oncol 33(22):2457-2463. https://doi.org/10.1200/JCO.

$572 \quad 2014.60 .5212$

573 24. Solass W, Sempoux C, Carr NJ, Detlefsen S, Bibeau F. Peritoneal sampling and

574 histological assessment of therapeutic response in peritoneal metastasis: proposal of 
575 the Peritoneal Regression Grading Score (PRGS). Pleura Peritoneum. 2016;1:99-107.

576 25. Solass W, Sempoux C, Carr NJ, Bibeau F, Neureiter D, Jäger T, Di Caterino T,

577 Brunel C, Klieser E, Fristrup CW, Mortensen MB, Detlefsen S. Reproducibility of the

578 peritoneal regression grading score for assessment of response to therapy in peritoneal

579 metastasis. Histopathology. 2019;74(7):1014-24. https://doiorg/10.1111/his.13829.

580 26. Passot G, You B, Boschetti G, Fontaine J, Isaac S, Decullier E, Maurice C, Vaudoyer

581 D, Gilly FN, Cotte E, Glehen O (2014) Pathological response to neoadjuvant

582 chemotherapy: a new prognosis tool for the curative management of peritoneal

$583 \quad$ colorectal carcinomatosis. Ann Surg Oncol 21(8):2608-2614.

584 27. Bhatt A, Yonemura Y, Mehta S, et al. Target region resection in patients undergoing 585 cytoreductive surgery for peritoneal metastases-is it necessary in absence of visible 586 disease? Eur J Surg Oncol. 2020;46(4 Pt A):582-589. doi:10.1016/j.ejso.2019.11.495

587 28. Bhatt A, Kammar P, Mehta S, Damodaran D, Zaveri S, Patel MD, Sinukumar S, Ray

588 M, Seshadri R. Chasing Rainbows? the Possibility of "Cure" in Patients with

589 Colorectal Peritoneal Metastases Undergoing Cytoreductive Surgery and HIPEC-a

590 Retrospective Study by INDEPSO. Indian J Surg Oncol. 2019 Feb;10(Suppl 1):49-56.

591 doi: 10.1007/s13193-019-00879-9. Epub 2019 Jan 30. PMID: 30886494; PMCID:

$592 \quad$ PMC6397129.

593 29. Spiliotis J, Kalles V, Kyriazanos I, et al. CRS and HIPEC in patients with peritoneal

594 metastasis secondary to colorectal cancer: The small-bowel PCI score as a predictor

595 of survival. Pleura Peritoneum. 2019;4(4):20190018. Published 2019 Oct 30.

596 doi:10.1515/pp-2019-0018

597

598 30. Villeneuve, L., Passot, G., Glehen, O. et al. The RENAPE observational registry:

599 rationale and framework of the rare peritoneal tumors French patient 
medRxiv preprint doi: https://doi.org/10.1101/2021.04.01.21254760; this version posted April 7, 2021. The copyright holder for this preprint (which was not certified by peer review) is the author/funder, who has granted medRxiv a license to display the preprint in perpetuity.

It is made available under a CC-BY-NC-ND 4.0 International license .

600

601

602

603

604

605

606

607

608

609

610

611

612

613

614

615

616

617

618

619

620

621

622

registry. Orphanet J Rare Dis 12, 37 (2017). https://doi.org/10.1186/s13023-017-

0571-y

31. Sugarbaker PH. Pseudomyxoma peritonei. A cancer whose biology is characterized by a redistribution phenomenon. Ann Surg. 1994;219(2):109-11

32. Bhatt, A., Glehen, O. Extent of Peritoneal Resection for Peritoneal Metastases:

Looking Beyond a Complete Cytoreduction. Ann Surg Oncol 27, 1458-1470 (2020). https://doi.org/10.1245/s10434-020-08208-Z

33. Yonemura Y, Canbay E, Ishibashi H. Prognostic factors of peritoneal metastases from colorectal cancer following cytoreductive surgery and perioperative chemotherapy. Sci World J. 2013;2013:978394

34. Kammar P, Bhatt A, Anam J, Waghoo S, Pandey J, Mehta S. Correlation between pelvic peritoneal disease and nodal metas- tasis in advanced ovarian cancer: can intraoperative findings define the need for systematic nodal dissection? Indian J Surg Oncol. 2019;10(Suppl 1):84-90.

35. Hynninen J, Lavonius M, Oksa S, Grenman S, Carpen O, Aura- nen A. Is perioperative visual estimation of intra-abdominal tumor spread reliable in ovarian cancer surgery after neoadjuvant chemotherapy? Gynecol Oncol. 2013;128: 229-32.

36. Berger Y, Jacoby H, Kaufmann MI, Ben-Yaacov A, Westreich G, Sharon I, et al. Correlation between intraoperative and pathological findings for patients undergoing cytoreductive surgery and hyperthermic intraperitoneal chemotherapy. Ann Surg Oncol. 2019;26(4):1103-9 


\section{Author contributions}

624 Study design and conceptualization- Aditi Bhatt, Olivier Glehen

625 Protocol writing- Aditi Bhatt, Olivier Glehen, Pascal Rousset, Nazim Benzerdjeb

626 Data acquisition and analysis- Aditi Bhatt, Pascal Rousset, Dario Baratti, Daniele Biacchi, Nazim Benzerdjeb, 627 Ignace de Hingh, Marcello Deraco, Vadim Gushcin, Praveen Kammar, Daniel Labow, Edward Levine, Brendan 628 Moran, Faheez Mohamed, David Morris, Sanket Mehta, Aviram Nissan, Mohammad Alyami, Mohammad 629 Adileh, Shoma Barat, Almog Ben Yacov, Kurtis Campbell, Kathleen Cummins-Perry, Delia Cortes-Guiral, 630 Noah Cohen, Loma Parikh, Samer Alammari, Galal Bashanfer, Anwar Alshukami, Kaushal Kundalia, Gaurav 631 Goswami,Vincent Van de Vlasakker, Michelle Sittig, Paolo Sammartino, Armando Sardi, Laurent Villeneuve, 632 Kiran Turaga, Yutaka Yonemura, Olivier Glehen

633 Interpretation of data- Aditi Bhatt, Pascal Rousset, Dario Baratti, Daniele Biacchi, Nazim Benzerdjeb, Ignace 634 de Hingh, Marcello Deraco, Vadim Gushcin, Praveen Kammar, Daniel Labow, Edward Levine, Brendan Moran, 635 Faheez Mohamed, David Morris, Sanket Mehta, Aviram Nissan, Mohammad Alyami, Mohammad Adileh,

636 Shoma Barat, Almog Ben Yacov, Kurtis Campbell, Kathleen Cummins-Perry, Delia Cortes-Guiral, Noah

637 Cohen, Loma Parikh, Samer Alammari, Galal Bashanfer, Anwar Alshukami, Kaushal Kundalia, Gaurav

638 Goswami,Vincent Van de Vlasakker, Michelle Sittig, Paolo Sammartino, Armando Sardi, Laurent Villeneuve,

639 Kiran Turaga, Yutaka Yonemura, Olivier Glehen

640 Statistical calculations- Praveen Kammar, Aditi Bhatt and Olivier Glehen

641 Critical review of the protocol and modifications- Dario Baratti, Marcello Deraco, Ignace de Hingh, Daniel

642 Labow, Edward Levine, David Morris, Brendan Moran, Faheez Mohamed, Sanket Mehta, Aviram Nissan,

643 Armando Sardi, Paolo Sammartino, Kiran Turaga, Yutaka Yonemura

644 Ethics and permissions- Aditi Bhatt, Laurent Villeneuve, Faheez Mohamed, Michelle Sittig, Kathleen

645 Cummins Perry, Shoma Barat, Mohammad Alyami

646 Manuscript writing - Aditi Bhatt, Olivier Glehen

647 Manuscript review and editing- Aditi Bhatt, Pascal Rousset, Dario Baratti, Daniele Biacchi, Nazim Benzerdjeb,

648 Ignace de Hingh, Marcello Deraco, Vadim Gushcin, Praveen Kammar, Daniel Labow, Edward Levine, Brendan

649 Moran, Faheez Mohamed, David Morris, Sanket Mehta, Aviram Nissan, Mohammad Alyami, Mohammad

650 Adileh, Shoma Barat, Almog Ben Yacov, Kurtis Campbell, Kathleen Cummins-Perry, Delia Cortes-Guiral,

651 Noah Cohen, Loma Parikh, Samer Alammari, Galal Bashanfer, Anwar Alshukami, Kaushal Kundalia, Gaurav

652 Goswami,Vincent Van de Vlasakker, Michelle Sittig, Paolo Sammartino, Armando Sardi, Laurent Villeneuve,

653 Kiran Turaga, Yutaka Yonemura, Olivier Glehen

655 Approval of the final version of the manuscript- Aditi Bhatt, Pascal Rousset, Dario Baratti, Daniele Biacchi, 656 Nazim Benzerdjeb, Ignace de Hingh, Marcello Deraco, Vadim Gushcin, Praveen Kammar, Daniel Labow, 657 Edward Levine, Brendan Moran, Faheez Mohamed, David Morris, Sanket Mehta, Aviram Nissan, Mohammad 658 Alyami, Mohammad Adileh, Shoma Barat, Almog Ben Yacov, Kurtis Campbell, Kathleen Cummins-Perry, 
659 Delia Cortes-Guiral, Noah Cohen, Loma Parikh, Samer Alammari, Galal Bashanfer, Anwar Alshukami, Kaushal

660 Kundalia, Gaurav Goswami,Vincent Van de Vlasakker, Michelle Sittig, Paolo Sammartino, Armando Sardi,

661 Laurent Villeneuve, Kiran Turaga, Yutaka Yonemura, Olivier Glehen

662

663 We affirm that all the authors have provided substantial contribution to this manuscript and are in agreement

664 with all aspects of the final version. All the authors agree to be accountable for all aspects of the work in

665 ensuring that questions related to the accuracy or integrity of any part of the work are appropriately investigated

666 and resolved.

667

668 Funding: This research received no specific grant from any funding agency in the public,

669 commercial or not-for-profit sectors

\section{Disclosures}

671 The authors have no disclosures

672 The authors have no conflicts of interest

673

\section{Figure legends}

675 Figure 1 Study flow-chart and guide to data capturing 
692 Table 1 Morphological description of peritoneal lesions on radiological, intraoperative and 693 pathological examination*

\begin{tabular}{|l|l|l|}
\hline Radiological evaluation & Visual inspection & Pathological examination \\
\hline Normal peritoneum & Normal peritoneum & Normal peritonuem \\
\hline Tumor nodule/deposit & Tumor nodule & Tumor nodule \\
\hline Scalloping & Confluent nodules & Clustering of nodules \\
\hline Calcification & Plaque & Thickening \\
\hline Thickening & Thickening & Scarring \\
\hline Confluent disease & Scarring & \\
\hline Infiltration of adipose tissue & Adhesion & \\
\hline Retraction & & \\
\hline
\end{tabular}

*The description/definition of each morphological type is provided at the end of the PCI 
medRxiv preprint doi: https://doi.org/10.1101/2021.04.01.21254760; this version posted April 7, 2021. The copyright holder for this preprint (which was not certified by peer review) is the author/funder, who has granted medRxiv a license to display the preprint in perpetuity.

It is made available under a CC-BY-NC-ND 4.0 International license .

706 Table 2 Score categorizing the pathological response to systemic chemotherapy in ovarian

cancer [23]

Criteria for chemotherapy response grade $(\mathrm{CRG})^{*}$

CRG 1 No or minimal tumor response. Mainly viable tumor with no or minimal regression-associated fibroinflammatory changes, limited to a few foci; cases in which it is difficult to decide between regression and tumor-associated desmoplasia or inflammatory cell infiltration

CRG 2 Appreciable tumor response amid viable tumor that is readily identifiable. Tumor is regularly distributed, ranging from multifocal or diffuse regression-associated fibroinflammatory changes with viable tumor in sheets, streaks, or nodules to extensive regression-associated fibroinflammatory changes with multifocal residual tumor, which is easily identifiable

CRG 3 Complete or near-complete response with no residual tumor or minimal irregularly scattered tumor foci seen as individual cells, cell groups, or nodules, up to $2 \mathrm{~mm}$ maximum size. Mainly regression-associated fibroinflammatory changes or, in rare cases, no or very little residual tumor in the complete absence of any inflammatory response. It is advisable to record whether there is no residual tumor or whether there is microscopic residual tumor present

*the term chemotherapy response grade is used instead of chemotherapy response score as in 709 the original and subsequent publications to avoid confusion with the term cytoreductive surgery (CRS)

712

713

714 
medRxiv preprint doi: https://doi.org/10.1101/2021.04.01.21254760; this version posted April 7, 2021. The copyright holder for this preprint (which was not certified by peer review) is the author/funder, who has granted medRxiv a license to display the preprint in perpetuity.

It is made available under a CC-BY-NC-ND 4.0 International license .

727 Table 3 The peritoneal regression grading score (PRGS) that can be used for different

728 primary tumours $[24,25]$

\begin{tabular}{|l|l|l|}
\hline \multirow{2}{*}{ Grade } & \multicolumn{2}{|l|}{ Peritoneal regression grading score (PRGS) } \\
\cline { 2 - 3 } $\begin{array}{l}\text { PRGS 1-complete } \\
\text { response }\end{array}$ & Tumor cells & Regression features \\
& $\begin{array}{l}\text { Abundant fibrosis and/or } \\
\text { acellular mucin pools and/ or } \\
\text { infarct-like necrosis }\end{array}$ \\
\hline PRGS 2-major response & $\begin{array}{l}\text { Regressive changes } \\
\text { predominant over tumor } \\
\text { cells }\end{array}$ & $\begin{array}{l}\text { Fibrosis and/or acellular mucin } \\
\text { pools and/or infarctlike necrosis } \\
\text { predominant over tumor cells }\end{array}$ \\
\hline PRGS 3-minor response & $\begin{array}{l}\text { Predominance of tumor } \\
\text { cells }\end{array}$ & $\begin{array}{l}\text { Tumor cells predominant over } \\
\text { fibrosis and/or acellular mucin } \\
\text { pools and/or infarct-like necrosis }\end{array}$ \\
\hline PRGS 4 -no response & $\begin{array}{l}\text { Solid growth of tumor } \\
\text { cells (visible at lowest } \\
\text { magnification) }\end{array}$ & \begin{tabular}{l} 
No regressive changes \\
\hline
\end{tabular}
\end{tabular}

733 Table 4 The Lyon-sud score for colorectal PM [26]

\begin{tabular}{|l|l|l|}
\hline \multicolumn{2}{|l|}{ Grade of response } & Type of response \\
\hline Complete response & No residual tumor cells & Fibrosis \\
\hline Major response & $1-49 \%$ residual tumor cells & Infarct-like necrosis \\
\hline Minor response & $>50 \%$ residual tumor cells & Colloid response \\
\hline
\end{tabular}

734

735

736 
medRxiv preprint doi: https://doi.org/10.1101/2021.04.01.21254760; this version posted April 7, 2021. The copyright holder for this preprint (which was not certified by peer review) is the author/funder, who has granted medRxiv a license to display the preprint in perpetuity. It is made available under a CC-BY-NC-ND 4.0 International license .

740 Table 5 Sample size for each primary tumor site

\section{1}

\begin{tabular}{|l|l|}
\hline & \\
\hline Colorectal cancer & 500 patients $(350$ patients who have received NACT) \\
\hline Ovarian cancer & 600 patients $(350$ undergoing interval CRS) \\
\hline Appendiceal primary & 300 patients \\
\hline Peritoneal mesothelioma & 100 patients \\
\hline Gastric cancer & 100 patients \\
\hline
\end{tabular}

742

743 

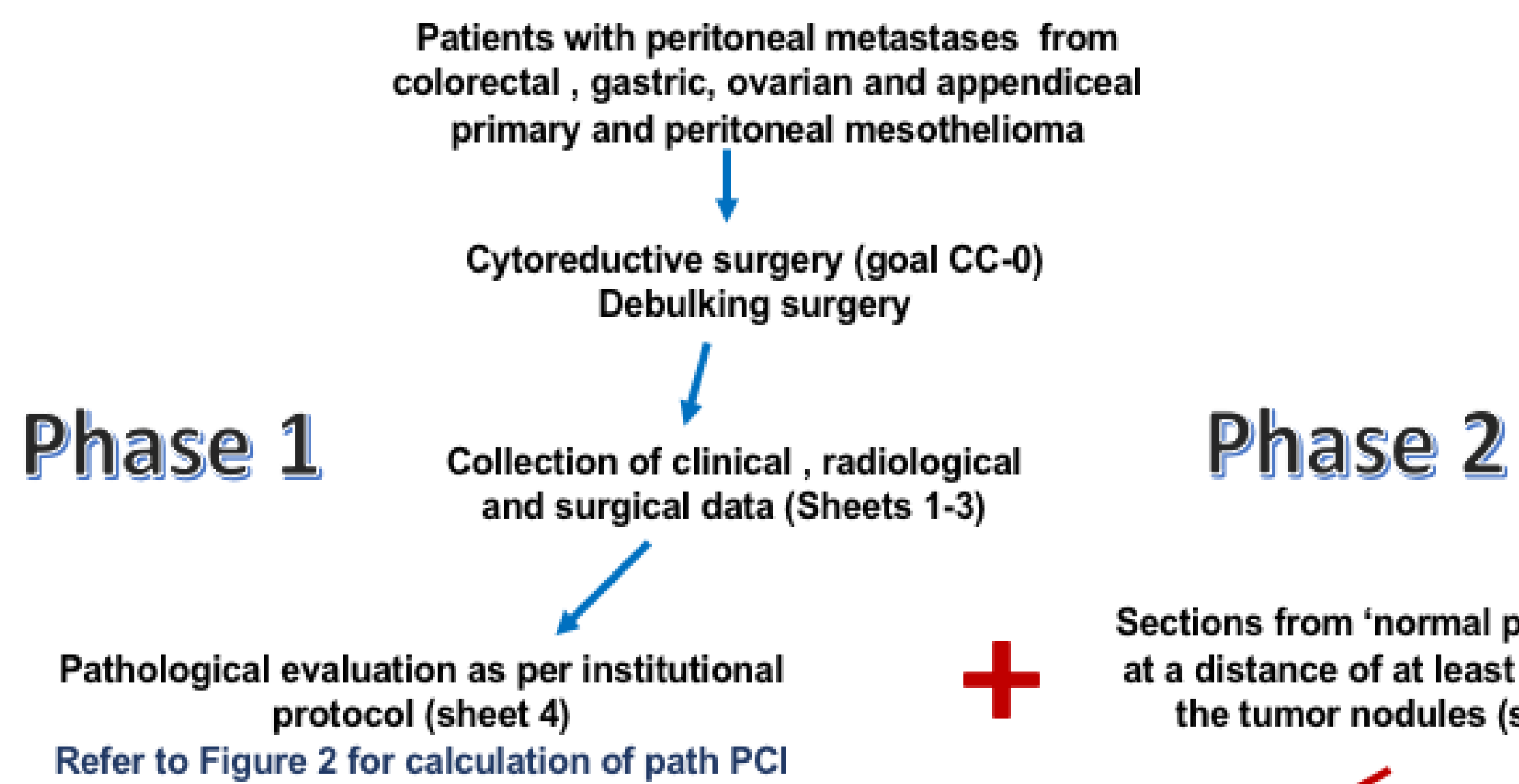

Sections from 'normal peritoneum' at a distance of at least $5 \mathrm{~mm}$ from the tumor nodules (sheet 4)
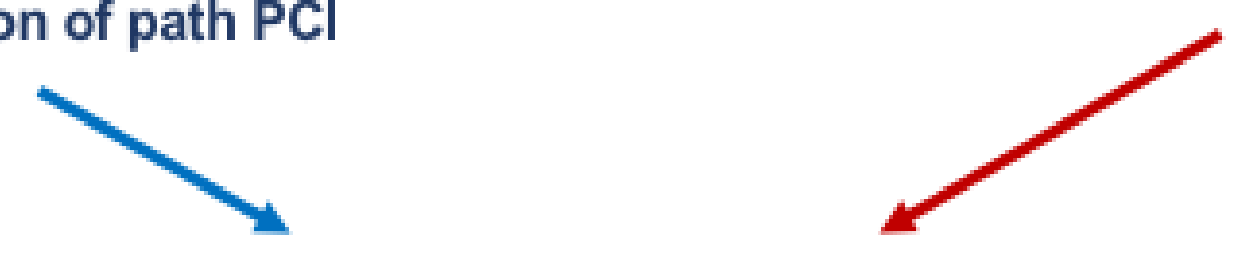

Follow up of patients at 1, 3 and 5 years from the date of recruitment

(sheet 5) 
Different peritoneal regions regions marked by the surgeon or sent individually

Areas of doubt marked

$\checkmark$

Identify of each peritoneal region and viscera and evaluate the maximum tumor diameter in each region

$\checkmark$

Group the resected peritoneum and viscera according to Sugarbaker's

$\mathrm{PCl}$ (refer to supplement 4 for identifying the structures in each region)

$\checkmark$

Confirm the presence of disease on microscopy for

each region and viscera (Absence of disease $=$ LSO)

MICROSCOPIC

$\checkmark$

Determine the maximum tumor diameter for each of the

EXAMINATION

13 regions (Lesion score) (Morphological description according to Table 1)

Summation of the score in each region

$\downarrow$

PATHOLOGICAL PCI 